\author{
Marquette University \\ e-Publications@Marquette
}

$11-2006$

\title{
Styrenic Polymer Nanocomposites Based on an Oligomerically- Modified Clay with High Inorganic Content
}

Jinguo Zhang

Marquette University

David D. Jiang

Marquette University

Dongyan Wang

Marquette University

Charles A. Wilkie

Marquette University, charles.wilkie@marquette.edu

Follow this and additional works at: https://epublications.marquette.edu/chem_fac

Part of the Chemistry Commons

\section{Recommended Citation}

Zhang, Jinguo; Jiang, David D.; Wang, Dongyan; and Wilkie, Charles A., "Styrenic Polymer Nanocomposites Based on an Oligomerically-Modified Clay with High Inorganic Content" (2006). Chemistry Faculty Research and Publications. 102.

https://epublications.marquette.edu/chem_fac/102 
Marquette University

\title{
e-Publications@Marquette
}

\section{Chemistry Faculty Research and Publications/College of Arts and Sciences}

This paper is NOT THE PUBLISHED VERSION; but the author's final, peer-reviewed manuscript. The published version may be accessed by following the link in th citation below.

Polymer Degradation and Stability, Vol. 91, No. 11 (November 2006): 2665-2674. DOI. This article is (C) Elsevier and permission has been granted for this version to appear in e-Publications@Marquette. Elsevier does not grant permission for this article to be further copied/distributed or hosted elsewhere without the express permission from Elsevier.

\section{Styrenic Polymer Nanocomposites Based on An Oligomerically-Modified Clay with High Inorganic Content}

\author{
Jinguo Zhang \\ Department of Chemistry, Marquette University, Milwaukee, WI \\ David D. Jiang \\ Department of Chemistry, Marquette University, Milwaukee, WI \\ Dongyan Wang \\ Department of Chemistry, Marquette University, Milwaukee, WI \\ Charles A. Wilkie \\ Department of Chemistry, Marquette University, Milwaukee, WI
}

\begin{abstract}
Clay was modified with an oligomeric surfactant containing styrene and lauryl acrylate units along with a small amount of vinylbenzyl chloride to permit the formation of an ammonium salt so that this can be attached to a clay. The oligomerically-modified clay contains $50 \%$ inorganic clay, and styrenic polymer nanocomposites, including those of polystyrene (PS), high-impact polystyrene (HIPS), styrene-acrylonitrile copolymer (SAN) and acrylonitrile-butadiene-styrene (ABS), were prepared by melt blending. The morphologies of the nanocomposites were evaluated by X-ray diffraction and transmission electron microscopy. Mixed intercalated/delaminated nanocomposites were formed for SAN and ABS while largely immiscible
\end{abstract}


nanocomposites were formed for PS and HIPS. The thermal stability and fire properties were evaluated using thermogravimetric analysis and cone calorimetry, respectively. The plasticization from the oligomeric surfactant was suppressed and the tensile strength and Young's modulus were improved, compared to similar oligomerically-modified clays with higher organic content.

\section{Keywords}

Nanocomposites, Oligomerically-modified clay, Styrenics, Fire retardancy

\section{Introduction}

The study of polymer-clay nanocomposites has been an active research area for some time. Nanocomposite formation based on small amounts of clay (3-10\%) can dramatically increase many properties of the polymer matrix including the mechanical, thermal and barrier properties $[1],[2],[3]$. Clay may also be a part of a new generation of flame retardants $[4],[5]$, since it can significantly reduce the peak heat release rate (PHRR), as measured by cone calorimetry. Depending on clay modification and polymer polarity, three kinds of nanocomposites can be formed, intercalated, delaminated and immiscible. In intercalated nanocomposites, the clay layers maintain their registry with an enlarged basal space. In delaminated nanocomposites, the clay layers are randomly distributed in the polymer matrix. The clay is not dispersed the nanometer level in immiscible nanocomposites, also known as microcomposites, but rather it is agglomerated in only a few locations.

Recent work from this laboratory [6], [7], [8], [9], [10], [11], [12], [13] has shown that oligomerically-modified clay can be used to produce nanocomposites of many polymers, including non-polar and polar polymers, by melt blending. The oligomerically-modified clays that have been previously studied in these laboratories include those based on styrene ${ }^{[7],[9]}$, methacrylate ${ }^{[8]}$, butadiene ${ }^{[13]}$, lauryl acrylate ${ }^{[10]}$, and the combination of lauryl acrylate with styrene [11], [12]. In each case, some amount of vinylbenzyl chloride (VBC) is also added; the presence of VBC enables the facile conversion of the oligomer into an ammonium salt, by quaternisation of an amine, which can then be ion exchanged onto a clay.

The surfactants prepared by the quaternisation of a terpolymer of styrene, lauryl acrylate and VBC is known as triclay [11]. Nanocomposites based on triclay showed good nano-dispersion and a large reduction in PHRR, compared with the virgin polymers. The main disadvantage of this oligomerically-modified clay is the large amount of plasticization, which has a detrimental effect on the mechanical properties. Three different surfactants have been prepared by holding the concentrations of styrene and lauryl acrylate constant and varying the amount of vinylbenzyl chloride. The first two have already been reported ${ }^{[11]}$, [12] and this paper is the report on the third clay with a similar composition, but with a varying organic content. Varying the amount of vinylbenzyl chloride increases the number of ammonium ions per chain, which can lead to pinning of the clay layers. A recent report of another oligomeric clay from the laboratory, which contains only styrene and vinylbenzyl chloride, found that even at an average of 1.2 ammonium ions per chain, pinning does occur and the clay is actually immiscible with polystyrene, even though it contains an oligomeric styrene surfactant $\frac{[14]}{\text {. }}$

The first version of triclay ${ }^{[11]}$ contained $5.3 \mathrm{~mol}$ of vinylbenzyl chloride per $100 \mathrm{~mol}$ of polymer so one would clearly expect pinning of the clay layers to occur and the XRD data imply that this does occur since the $d$ spacing of the clay is $3.7 \mathrm{~nm}$ and the same $d$-spacing is observed in styrenic nanocomposites with this clay. On the other hand, the TEM images show the presence of both tactoids as well as individual clay layers, which suggests that at least some of the clay layers are not pinned together. In triclay II 12$]$, the content of vinylbenzyl chloride increases to $9.1 \mathrm{~mol}$ per $100 \mathrm{~mol}$ of polymer; the $d$-spacing is still $3.7 \mathrm{~nm}$ and the TEM images show that good nano-dispersion has been achieved and that the individual clay layers may again be seen. The clay dispersion is a little better with the lower VBC content clay (triclay) but it is still acceptable with the higher clay content material (triclay II). The original triclay contained $75 \%$ organic while triclay II was $62.5 \%$ organic. These styrenic polymer-clay nanocomposites were studied using TGA, cone calorimetry and the evaluation of mechanical properties. It was found that the reduction in the peak heat release rate, as measured by cone calorimetry, was equivalent to the best reduction observed for other organically-modified clays, which suggests that good nano-dispersion had been achieved. On the other hand, the mechanical properties showed plasticization, presumably due to the high organic content of the clays. 
In this paper, another oligomerically-modified clay, containing an even higher content of VBC and a lower organic content (50\%), is reported. The intent of this work is to determine if good nano-dispersion may be obtained with the greater opportunity of pinning of the clay layers and to see if the reduced organic content reduces the plasticization and therefore improves the mechanical properties of these nanocomposites.

\section{Experimental}

\subsection{Materials}

Acrylonitrile-butadiene-styrene copolymer (ABS) (melt index $230{ }^{\circ} \mathrm{C} / 3.8 \mathrm{~kg}, 2.6 \mathrm{~g} / 10 \mathrm{~min}$ ) and highimpact polystyrene (HIPS) (STYRON 478) were acquired from the Dow Chemical Company. Styrene-acrylonitrile copolymer (SAN) was provided by Cheil Industries, Inc. Sodium montmorillonite was provided by Southern Clay Products, Inc. Polystyrene (melt index $200^{\circ} \mathrm{C} / 5.0 \mathrm{~kg}, 7.50 \mathrm{~g} / 10 \mathrm{~min}$ ), vinylbenzyl chloride (VBC), styrene (St), lauryl acrylate and 2,2'-azobisisobutyronitrile (AIBN) were acquired from the Aldrich Chemical Company, Inc.

\subsection{Synthesis of oligomer surfactant}

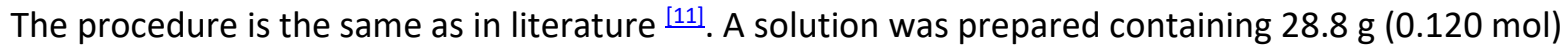
lauryl acrylate, $12.5 \mathrm{~g}(0.120 \mathrm{~mol})$ styrene and $9.2 \mathrm{~g}(0.06 \mathrm{~mol})$ vinylbenzyl chloride in $150 \mathrm{ml}$ tetrahydrofuran (THF) in a $500 \mathrm{ml}$ three-neck round bottom flask, equipped with a magnetic stirrer, condenser and a nitrogen inlet and outlet. The solution was first stirred for $10 \mathrm{~min}$ and then gently refluxed under nitrogen for $10 \mathrm{~min}$ and $3.3 \mathrm{~g}(0.02 \mathrm{~mol})$ AIBN was added to initialize the polymerization. The system was kept at a gentle reflux for $12 \mathrm{~h}$. The terpolymer was precipitated by pouring the solution into a large amount of methanol and $46 \mathrm{~g}$ of a colorless oligomer was collected after filtration. ${ }^{1} \mathrm{H}$ NMR: $\left(\mathrm{CDCl}_{3}, \mathrm{ppm}\right) 7.1(\mathrm{br}, 8 \mathrm{H}, \mathrm{ArH}), 6.7(\mathrm{br}, 6 \mathrm{H}, \mathrm{ArH}), 4.5(\mathrm{br}, 2 \mathrm{H}$, $\left.\mathrm{ArCH}_{2} \mathrm{Cl}\right), 3.8\left(\mathrm{br}, 4 \mathrm{H},-\mathrm{OCH}_{2}-\right)$, 2.3(br, 5H, $\left.\mathrm{ArCH}-+-\mathrm{OCOCH}-\right), 1.9\left(\mathrm{br}, 10 \mathrm{H}, \mathrm{ArCHCH}_{2}+-\mathrm{OCHCH}_{2}-\right), 1.6(\mathrm{br}, 4 \mathrm{H},-$ $\left.\mathrm{OCOCHCH}{ }_{2}-\right), 1.3\left(\mathrm{br}, 36 \mathrm{H},-\left(\mathrm{CH}_{2}\right)_{9}-\right), 0.9\left(\mathrm{t}, 6 \mathrm{H},-\mathrm{CH}_{3}\right)$. The integration of this NMR data gives a composition of lauryl acrylate:styrene:vinylbenzyl chloride of 2:2:1, which is the same as the ratio of starting materials in the synthesis. There are six protons at $0.9 \mathrm{ppm}$, which may be assigned as the methyl group in lauryl acrylate and this gives two units of lauryl acrylate; two protons appear at $4.5 \mathrm{ppm}$ and these are assigned to the benzyl protons and this gives one benzyl chloride; there are six protons at $6.7 \mathrm{ppm}$ and these include those from styrene and VBC (two from VBC and four from styrene), which gives two styrene units and the final composition as noted above.

To synthesize the surfactant, $12 \mathrm{~g}$ triethylamine (this is a large excess) was added to a solution of $46 \mathrm{~g}$ copolymer in $200 \mathrm{ml} \mathrm{THF}$ in a $500 \mathrm{ml}$ round bottom flask. The solution was stirred at room temperature for $1 \mathrm{~h}$ and then maintained at $50{ }^{\circ} \mathrm{C}$ for $10 \mathrm{~h}$ under nitrogen. The oligomeric surfactant was precipitated from methanol, and then kept at $70^{\circ} \mathrm{C}$ under vacuum for $12 \mathrm{~h}$ and $50 \mathrm{~g}$ of the surfactant was collected. A new broad peak in the NMR spectrum at $3.4 \mathrm{ppm}$ may be assigned as the methylene group attached to the nitrogen of the ammonium salt, while the methyl group adjacent to the methylene is in the $1.3 \mathrm{ppm}$ region.

\subsection{Preparation of oligomerically-modified clay: triclay III}

A $30 \mathrm{~g}$ portion of sodium montmorillonite in $500 \mathrm{ml} \mathrm{THF} / \mathrm{H}_{2} \mathrm{O}$ (50:50) was stirred overnight to obtain a well-dispersed suspension and $30 \mathrm{~g}$ of the surfactant was dissolved in $150 \mathrm{ml} \mathrm{THF}$. A $120 \mathrm{ml}$ portion of the salt solution was slowly added to the dispersed clay and the system was vigorously stirred for $12 \mathrm{~h}$, then the remaining surfactant solution was added drop-wise. The modified clay quickly settled to the bottom after stirring was stopped. The supernatant liquid was removed and the modified clay was washed with another $500 \mathrm{ml}$ portion of $\mathrm{THF} / \mathrm{H}_{2} \mathrm{O}$ (50:50). The modified clay was collected by filtration and dried in a vacuum oven at $80^{\circ} \mathrm{C}$ for $24 \mathrm{~h}$ and $60 \mathrm{~g}$ of oligomerically-modified clay, triclay III, was obtained.

\subsection{Preparation of polymer-clay nanocomposites}

The inorganic content in triclay III is $50 \%$, as shown by TGA, which is significantly higher than that in the other, related, oligomerically-modified clays produced in this laboratory. Nanocomposites were prepared through melt intercalation in a Brabender mixer at $60 \mathrm{rpm}$ at $185^{\circ} \mathrm{C}$ for $10 \mathrm{~min}$. The calculated amounts of polymer and triclay III were charged to the Brabender mixer at the same time. The composites were removed from the chamber after $10 \mathrm{~min}$ of blending and allowed to cool to room temperature. This higher inorganic 
content clay required a longer mixing time in order to achieve a homogeneous distribution of the clay in the polymer; visual observation at shorter mixing times showed an obvious lack of homogeneity. The composition of the nanocomposites is given in Table 1.

Table 1. Composition of polymer-clay nanocomposites

\begin{tabular}{|l|l|l|l|}
\hline No. & Polymer & Triclay III & Inorganic clay loading (\%) \\
\hline 1 & 98 & 2 & 1 \\
\hline 2 & 94 & 6 & 3 \\
\hline 3 & 90 & 10 & 5 \\
\hline
\end{tabular}

\subsection{Instrumentation}

X-ray diffraction (XRD) measurements were performed on a Rigaku Geiger Flex, 2-circle powder diffractometer equipped with $\mathrm{Cu}-\mathrm{K} \alpha$ generator $\left(\lambda=1.5404 \AA\right.$ ) at $50 \mathrm{kV}$ and $1 \mathrm{~mA}$, scanning from $1^{\circ}$ to $10^{\circ}$ at $0.1^{\circ}$ step size; XRD samples were molded into $20 \mathrm{~mm} \times 15 \mathrm{~mm} \times 1 \mathrm{~mm}$ plaques using a heated press. Bright field transmission electron microscopy (TEM) images were obtained at $120 \mathrm{kV}$, under low-dose conditions, with a Phillips 400T electron microscopy. The sample was ultramicrotomed with a diamond knife on a Leica Ultracut UCT microtome at room temperature to give a $70 \mathrm{~nm}$ thick section. The section was transferred from water to carbon-coated Cu grids of 200 mesh. The contrast between the layered silicate and the polymer phase was sufficient for imaging, so no heavy metal staining of sections prior to imaging was required. Thermogravimetric analysis was performed on a TA SDT 2960 unit under nitrogen. The approximately $15 \mathrm{mg}$ samples were first equilibrated at $100{ }^{\circ} \mathrm{C}$, and then heated to $600^{\circ} \mathrm{C}$ at a rate of $20^{\circ} \mathrm{C} / \mathrm{min}$. Temperatures are reproducible to $\pm 3{ }^{\circ} \mathrm{C}$ while mass is repeatable to $\pm 2 \%$. Cone calorimetry was carried out on an Atlas CONE-2 according to ASTM E 1354 at an incident flux of $35 \mathrm{~kW} / \mathrm{m}^{2}$ using a cone shaped heater. Exhaust flow was set at $24 \mathrm{l} / \mathrm{s}$ and the spark was continuous until the sample was ignited. Cone samples were prepared by compression molding the composites into $100 \mathrm{~mm} \times 100 \mathrm{~mm} \times 3 \mathrm{~mm}$ square plaques. Typical results from cone calorimetry are reproducible to within about $\pm 10 \%$. These uncertainties are based on many runs in which thousands of samples have been combusted ${ }^{[15]}$. Tensile properties were measured using an MTS Alliance RT/5 tensile test machine at a crosshead speed of $5 \mathrm{~mm} / \mathrm{min}$. The reported values are the average of five determinations.

\section{Results and discussion}

\subsection{X-ray diffraction}

The X-ray diffraction (XRD) trace of triclay III is shown in Fig. 1; the peak appears at the same position as in triclay $\stackrel{[11]}{ }$ and triclay $11 \stackrel{[12]}{~}$. The modified clay has a strong reflection located at $2.4^{\circ}$, corresponding to a $d$ spacing of $3.7 \mathrm{~nm}$. The second-order and third-order reflections are also seen in the pattern.

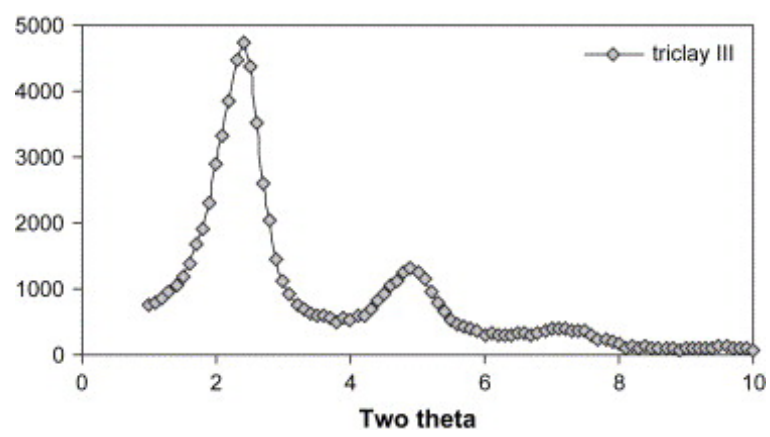

Fig. 1. X-ray diffraction trace of the oligomerically-modified clay, triclay III.

Three different inorganic clay loadings were used in this study: $1 \%, 3 \%$ and $5 \%$. Because triclay III contains $50 \%$ inorganic clay, the corresponding amounts of triclay III that were used are $2 \%, 6 \%$ and $10 \%$. The XRD traces for the polymer nanocomposites are shown in Fig. 2, Fig. 3, Fig. 4, Fig. 5. All of the PS and HIPS nanocomposites exhibit a strong reflection at $2.4^{\circ}$ with second- and third-order reflections. The lack of a change 
in the $2 \vartheta$ position is a common phenomenon for polymer nanocomposites based on oligomerically-modified clays [11], [12]. A possible explanation is that the multiple ammonium ions on each oligomeric chain enable a surfactant molecule to bind to two or more clay layers, leading to pinning of the clay layers. The presence of the 002 and 003 reflections, in addition to that from the 001, suggests a structure which is not disordered. The fact that all three versions of triclay, which contain more than enough vinylbenzyl chloride to lead to multiple ammonium ions per chain, show the same $d$-spacing leads one to suggest that all three of these clays do pin the clay layers.

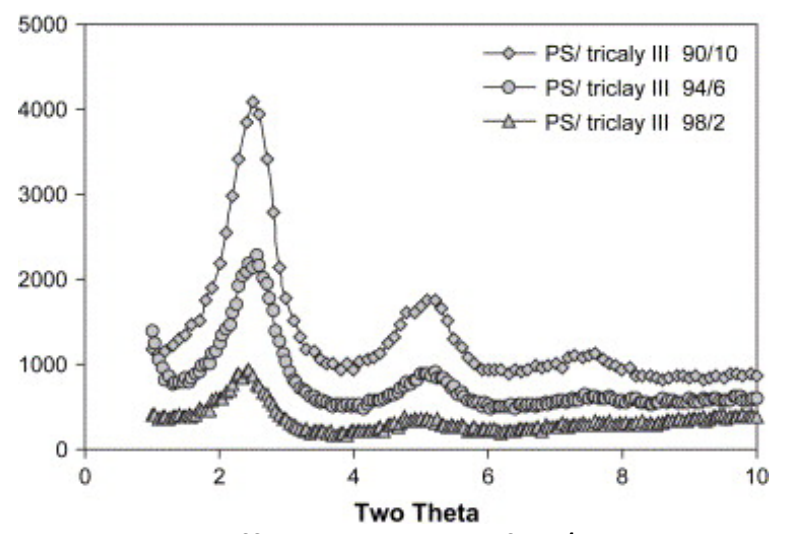

Fig. 2. X-ray diffraction traces of PS/triclay III nanocomposites.

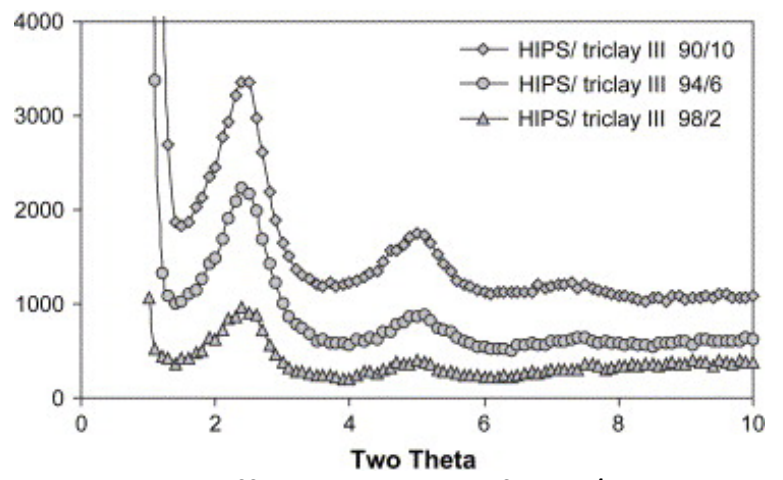

Fig. 3. X-ray diffraction traces of HIPS/triclay III nanocomposites.

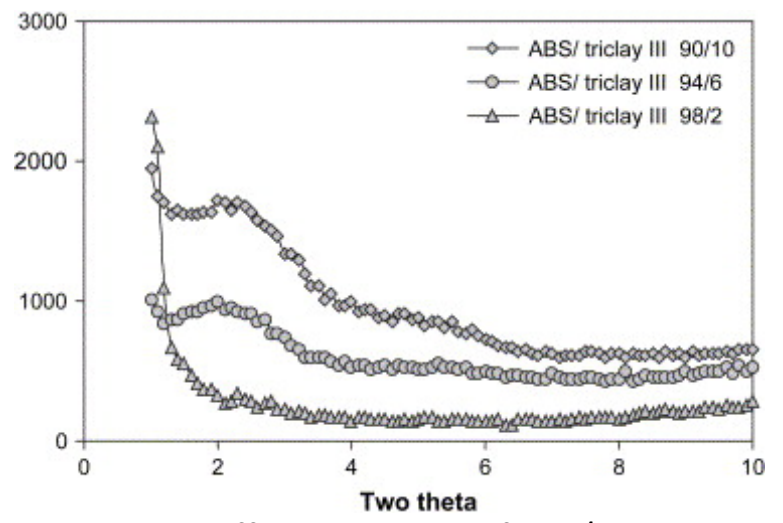

Fig. 4. X-ray diffraction traces of ABS/triclay III nanocomposites. 


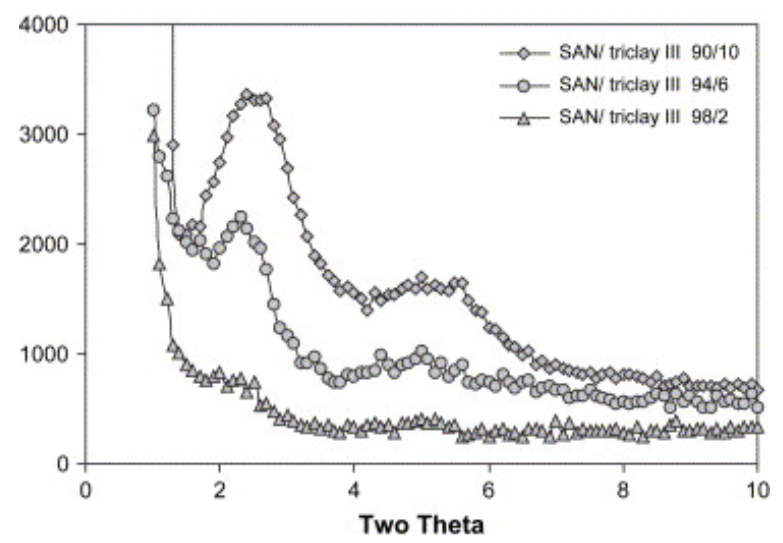

Fig. 5. X-ray diffraction traces of SAN/triclay III nanocomposites.

The ABS nanocomposite shows a broadened peak at $2.4^{\circ}$ and the second- and third-order reflections are lost. These ABS nanocomposites might be expected to show either delamination or disordering. For SAN nanocomposites, the peak is sharper than in ABS but much broader than in PS and HIPS. This XRD data suggest that PS and HIPS have a similar morphology and that it is a different morphology than what is seen in SAN and ABS.

It is difficult to imagine how pinned clay layers can give different morphologies with different polymers. If the clay layers were truly pinned, one would imagine that it would not be possible to have either disorder or delamination of the clay. Another possible explanation of the constancy of the $d$-spacing for all of the triclay styrenic nanocomposites is that the clay gallery is already well expanded by the surfactant so no further expansion is needed for polymer entry into the gallery space. This will lead to different morphologies for the various polymers and the varying amounts of vinylbenzyl chloride.

\subsection{Transmission electron microscopy}

$X$-ray diffractions alone should never be used alone to determine the morphology of a nanocomposite ${ }^{[16]}$; the use of TEM to image the clay in the polymer is required and has been used in this study. TEM images of the styrenic polymer nanocomposites at $5 \%$ inorganic clay loading were obtained and these are shown in Fig. 6, Fig. 7, Fig. 8, Fig. 9. For PS and HIPS nanocomposites, clay tactoids are obvious in the low magnification images while intercalated clay layers are apparent in the high magnification images. These systems should be described as largely immiscible nanocomposites or possibly as mixed intercalated/immiscible. For the ABS and SAN nanocomposites, the extent of nano-dispersion is much better in the low magnification images and individual clay layers, both in registry and not in registry are seen at high magnification. These should be described as mixed intercalated/delaminated nanocomposites. There is a good agreement between XRD and TEM. The sharp XRD peaks for PS and HIPS indicate the immiscibility while the broader peaks for the other polymers lead one to suspect that nano-dispersion may have occurred.

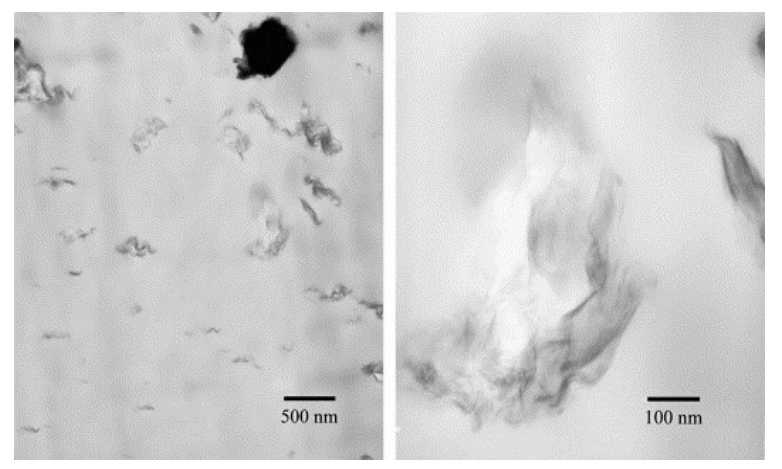

Fig. 6. TEM images of PS nanocomposite at 5\% inorganic clay loading. 

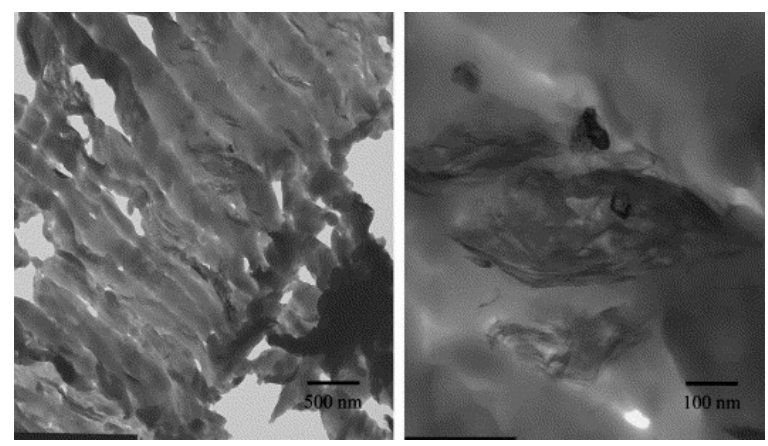

Fig. 7. TEM images of HIPS nanocomposite at $5 \%$ inorganic clay loading.

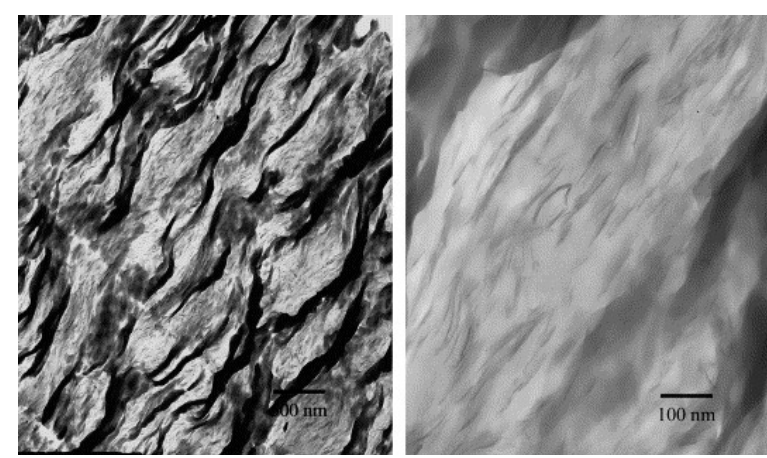

Fig. 8. TEM images of ABS nanocomposite at $5 \%$ inorganic clay loading.

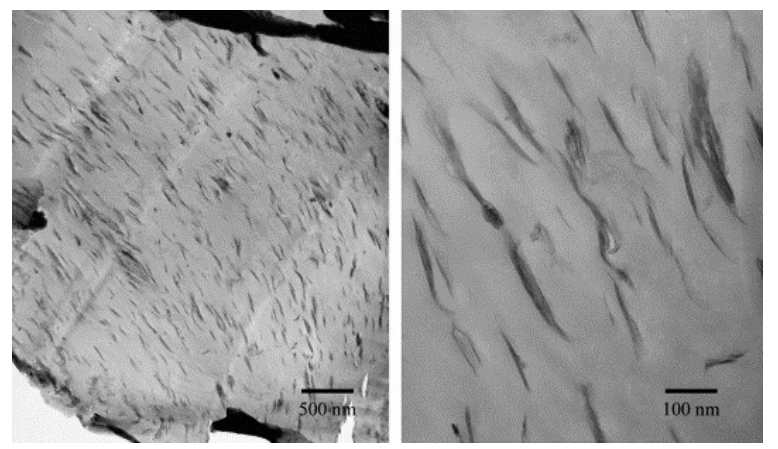

Fig. 9. TEM images of SAN nanocomposite at $5 \%$ inorganic clay loading.

With respect to possible pinning of the clay layers, the XRD and TEM data seem to be contradictory. The constancy of the $d$-spacing for all versions of triclay may imply that the layers are pinned together but the TEM images show the presence of individual clay layers, which do not support complete pinning. Also, the different XRD patterns, both for the different polymers and the different editions of the clay, support the notion that there is no complete pinning of clay layers. The TEM images show the presence of tactoids for some polymers but individual clay layers for other polymers. In the earlier editions of triclay, individual clay layers were also noted in the higher magnification TEM images. One cannot, at this stage, make a definitive statement on pinning of clay layers and this will require further investigation.

\subsection{Thermogravimetric analysis}

The thermal stability of clay and its nanocomposites was measured by TGA. The data available from TGA include $T_{0.1}$, the temperature at which $10 \%$ degradation occurs, which is taken as the onset temperature of degradation, $T_{0.5}$, the temperature at which $50 \%$ degradation occurs, which is another measure of thermal stability, and the non-volatile fraction at $600{ }^{\circ} \mathrm{C}$, denoted as char. The data for the polymers and their nanocomposites are summarized in Table 2 and are shown graphically in Fig. 11, Fig. 12, Fig. 13, Fig. 14. Previous work on polystyrene nanocomposite formation based on organically-modified clay by bulk polymerization

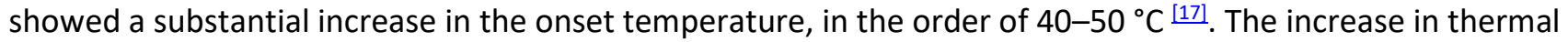


stability is much smaller when the nanocomposites are prepared by melt blending. For instance, polystyrene clay hybrids based on Cloisite $10 \mathrm{~A}$ and $20 \mathrm{~A}$ by melt blending showed about a $10^{\circ} \mathrm{C}$ increase in the onset temperature. It is generally believed that the nanocomposite formation is more effective for in situ polymerization than melt blending, which leads to the difference in the enhancement of thermal stabilities.

Table 2. TGA data, in nitrogen, for styrenic polymer-clay nanocomposites

\begin{tabular}{|c|l|l|l|l|}
\hline & Triclay III & $\boldsymbol{T}_{\mathbf{0 . 1}}\left({ }^{\circ} \mathbf{C}\right)$ & $\left.\boldsymbol{T}_{0.5} \mathbf{(}^{\mathbf{}} \mathbf{C}\right)$ & Char at $\mathbf{6 0 0} \mathbf{~}^{\mathbf{C}} \mathbf{~ ( \% )}$ \\
\hline PS & & & & \\
\hline 100 & 0 & 398 & 426 & 0 \\
\hline 98 & 2 & 408 & 442 & 2 \\
\hline 94 & 6 & 414 & 448 & 4 \\
\hline 90 & 10 & 410 & 448 & 6 \\
\hline HIPS & & & & \\
\hline 100 & 0 & 425 & 449 & 0 \\
\hline 98 & 2 & 427 & 454 & 3 \\
\hline 94 & 6 & 424 & 458 & 4 \\
\hline 90 & 10 & 422 & 459 & 8 \\
\hline SAN & & & & \\
\hline 100 & 0 & 407 & 430 & 2 \\
\hline 98 & 2 & 402 & 430 & 4 \\
\hline 94 & 6 & 402 & 434 & 6 \\
\hline 90 & 10 & 404 & 435 & 7 \\
\hline ABS & & & & \\
\hline 100 & 0 & 404 & 431 & 0 \\
\hline 98 & 2 & 413 & 442 & 4 \\
\hline 94 & 6 & 411 & 445 & 7 \\
\hline 90 & 10 & 404 & 441 & 10 \\
\hline
\end{tabular}

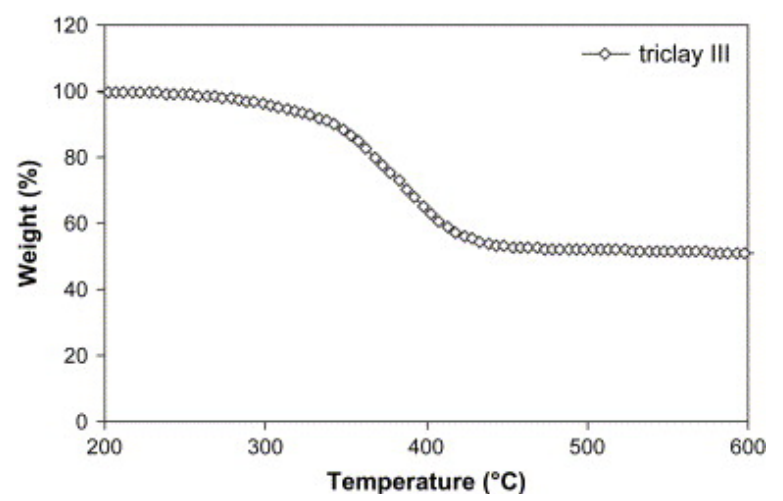

Fig. 10. TGA curve for the clay. 


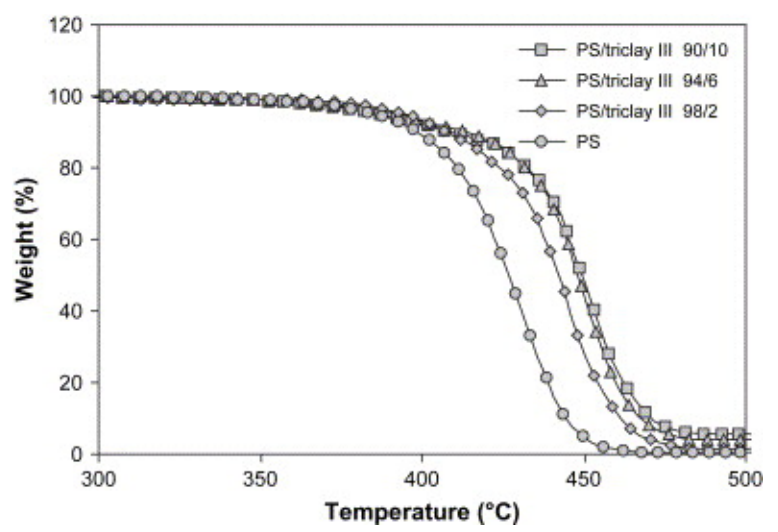

Fig. 11. TGA curves for PS/clay nanocomposites.

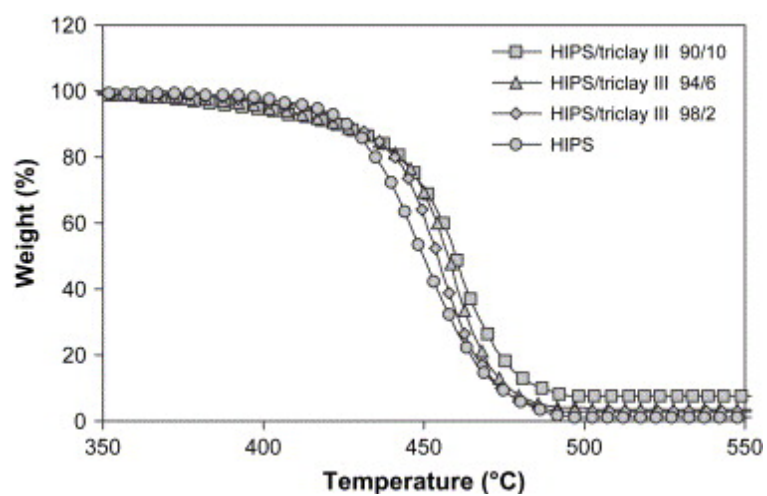

Fig. 12. TGA curves for HIPS/clay nanocomposites.

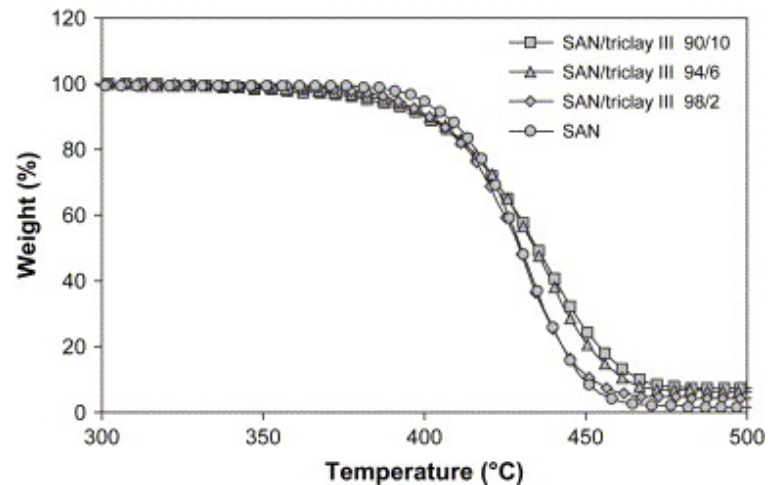

Fig. 13. TGA curves for SAN/clay nanocomposites.

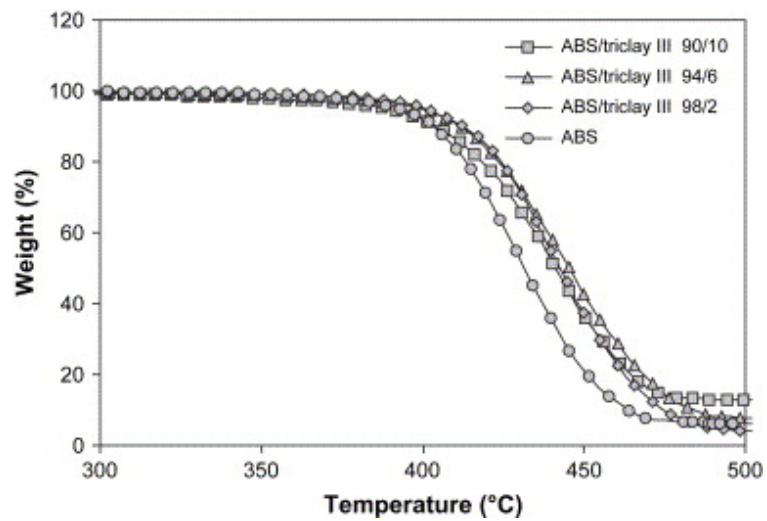

Fig. 14. TGA curves for ABS/clay nanocomposites. 
From the work on triclay and triclay II with styrenic polymers, the nanocomposites usually show lower $T_{0.1}$ and higher $T_{0.5}$ compared with the virgin polymers, presumably due to the large amount of oligomer that is introduced to the hybrids. From Fig. 10, the 10\% mass loss temperature of the oligomerically-modified clay is $342{ }^{\circ} \mathrm{C}$ and that of char is $50 \%$, indicating the inorganic content of the modified clay. This onset temperature is $50-70^{\circ} \mathrm{C}$ lower than that of the styrenic polymers used in this study. The PS and ABS nanocomposites show some improvement while the change for HIPS and SAN nanocomposites is not significant. The PS nanocomposite with $3 \%$ inorganic clay shows a $16^{\circ} \mathrm{C}$ enhancement in the onset temperature. For ABS nanocomposites, the maximum improvement is $7{ }^{\circ} \mathrm{C}$ with $1 \%$ inorganic clay. The mid-point of the degradation, $T_{0.5}$, for PS, HIPS and ABS nanocomposites shows some improvement. Again, polystyrene nanocomposites have the biggest improvement compared with the rest of the polymer nanocomposites in this study. The $T_{0.5}$ of PS nanocomposite containing $1 \%$ inorganic clay is $16^{\circ} \mathrm{C}$ higher than that of PS while with $3 \%$ and $5 \%$ inorganic clay, the PS nanocomposites exhibit a $22^{\circ} \mathrm{C}$ improvement. The biggest improvement for HIPS is $10{ }^{\circ} \mathrm{C}$ for the nanocomposite containing $5 \%$ inorganic clay. For the ABS system, the biggest improvement is $14{ }^{\circ} \mathrm{C}$ for ABS with $3 \%$ inorganic clay. The $T_{0.5}$ of SAN nanocomposites shows basically no change compared with virgin SAN. The char formation at $600^{\circ} \mathrm{C}$ is in good agreement with the amount of inorganic clay in the nanocomposite; no polymeric char is formed and all of the polymer must degrade. The TGA results for all three versions of triclay are quite similar; the variation in the inorganic content in the oligomerically-modified clay does not have any significant effect on the thermal stability in an inert atmosphere.

\subsection{Cone calorimetry}

The fire properties of the polymers and their clay nanocomposites were evaluated by cone calorimetry. The data obtained include the time to ignition $\left(t_{\text {ign }}\right)$; the heat release rate, and especially its peak value (PHRR); the specific extinction area (SEA), a measure of the amount of smoke produced during the combustion; the mass loss rate (MLR); and the total heat released (THR), a measure of how much polymer is actually combusted. Besides the fire properties, cone calorimetry also provides information on nanocomposite formation, since polymer-clay microcomposites give essentially no reduction in the peak heat release rate and mass loss rate while polymer-clay nanocomposites can give significant reductions [15], [18], [19]. Since TEM samples are only a very small portion of the material, while cone calorimetry is a bulk measurement, the cone results may provide a more reliable measure of nano-dispersion.

The heat release rate curves for the styrenic polymers and their nanocomposites are shown graphically in Fig. 15, Fig. 16, Fig. 17, Fig. 18 and the data are tabulated in Table 3 . The PS nanocomposites show a reduction in PHRR between $20 \%$ and $30 \%$ at all clay levels, which is significantly lower than the value expected from previous work (50-60\%) [11], [14]. This indicates some immiscible component, in agreement with XRD and TEM. For HIPS nanocomposites, significant reduction is evident only when the inorganic clay loading reaches $5 \%$; the reduction is $23 \%$ and the $A B S$ nanocomposite with $5 \%$ organically-modified clay achieves a $35 \%$ reduction in PHRR [20]. Only SAN nanocomposites achieve comparable reductions in the PHRR as have been seen in the previous work; $38 \%$ is the maximum achieved in this work. To reiterate, the reductions in the PHRR are smaller for PS, HIPS and ABS than that have been achieved with other systems; it is only with SAN that this clay behaves as well in the reduction in the peak heat release rate as do previously studied clays [11], [12], [21], [22]. For PS and HIPS systems, the time to ignition $\left(t_{\text {ign }}\right)$ becomes shorter with increasing clay content, which is usually seen in polymer-clay nanocomposites. The time to ignition $\left(t_{\text {ign }}\right)$ is basically unchanged for SAN and ABS nanocomposites compared to the virgin polymers. The reduction in the mass loss rate (MLR) is proportional to the reduction of PHRR for the nanocomposites. For all styrenic polymer-clay nanocomposites, the specific extinction area, SEA, is unchanged or slightly increased in the presence of clay and there is no change in total heat released for nanocomposites, which is expected and this indicates that the entire polymer does burn. 


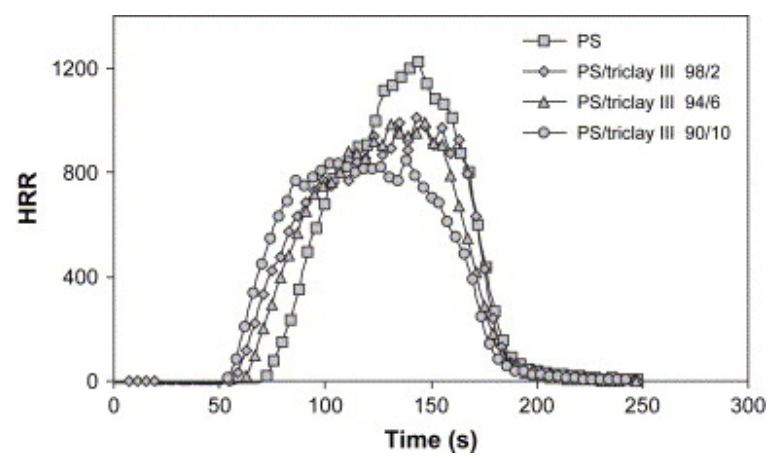

Fig. 15. Comparison of the heat release rate (HRR) plots for PS and its clay nanocomposites at $35 \mathrm{~kW} / \mathrm{m}^{2}$ heat flux.

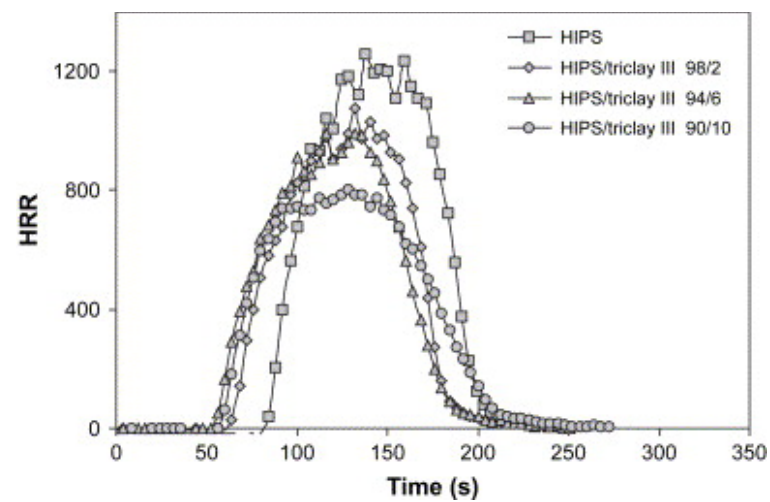

Fig. 16. Comparison of the heat release rate (HRR) plots for HIPS and its clay nanocomposites at $35 \mathrm{~kW} / \mathrm{m}^{2}$ heat flux.

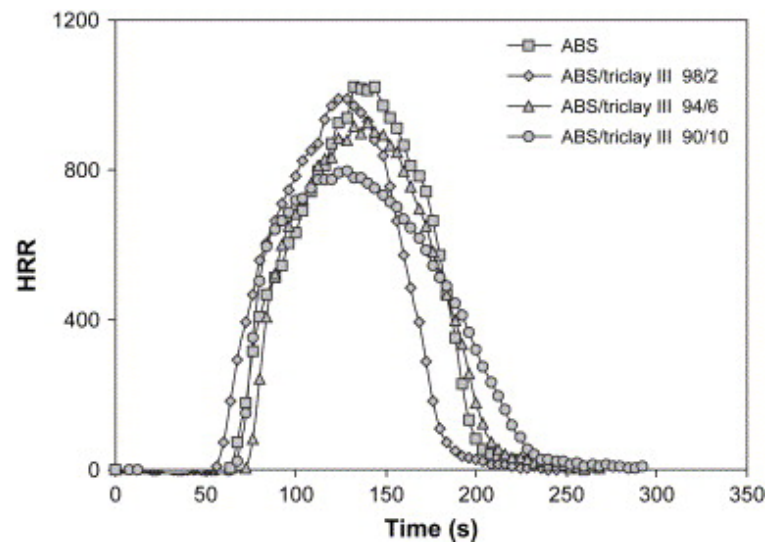

Fig. 17. Comparison of the heat release rate (HRR) plots for ABS and its clay nanocomposites at $35 \mathrm{~kW} / \mathrm{m}^{2}$ heat flux. 


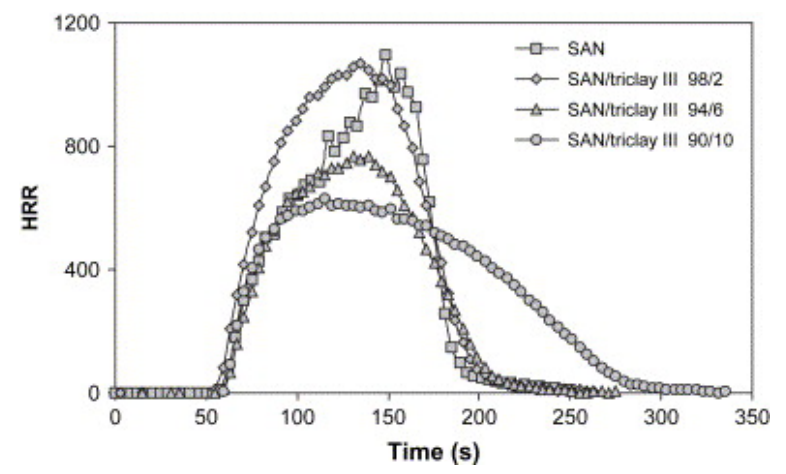

Fig. 18. Comparison of the heat release rate (HRR) plots for SAN and its clay nanocomposites at $35 \mathrm{~kW} / \mathrm{m}^{2}$ heat flux.

Table 3. Cone calorimeter data for styrenic polymers and their nanocomposites

\begin{tabular}{|c|c|c|c|c|c|c|}
\hline & Triclay III & $t_{\text {ign }}(s)$ & PHRR $\left(\mathrm{kW} / \mathrm{m}^{2}\right)$ (\% reduction) & $\operatorname{SEA}\left(\mathrm{m}^{2} / \mathrm{kg}\right)$ & $\operatorname{MLR}\left(\mathrm{g} / \mathrm{s} \mathrm{m}^{2}\right)$ & THR $\left(\mathrm{MJ} / \mathrm{m}^{2}\right)$ \\
\hline \multicolumn{7}{|l|}{ PS } \\
\hline 100 & 0 & $62 \pm 3$ & $1289 \pm 60$ & $1039 \pm 11$ & $36 \pm 1$ & $82 \pm 1$ \\
\hline 98 & 2 & $53 \pm 3$ & $1035 \pm 84(20)$ & $1082 \pm 20$ & $30 \pm 2$ & $81 \pm 3$ \\
\hline 94 & 6 & $54 \pm 2$ & $999 \pm 78(23)$ & $1139 \pm 40$ & $30 \pm 2$ & $77 \pm 1$ \\
\hline 90 & 10 & $45 \pm 3$ & $871 \pm 12(32)$ & $1199 \pm 29$ & $27 \pm 0$ & $79 \pm 3$ \\
\hline \multicolumn{7}{|c|}{ HIPS } \\
\hline 100 & 0 & $66 \pm 3$ & $1234 \pm 77$ & $1159 \pm 2$ & $32 \pm 0$ & $87 \pm 2$ \\
\hline 98 & 2 & $59 \pm 1$ & $1065 \pm 9(14)$ & $1185 \pm 16$ & $30 \pm 2$ & $83 \pm 0$ \\
\hline 94 & 6 & $47 \pm 4$ & $1039 \pm 41(16)$ & $1232 \pm 8$ & $29 \pm 1$ & $84 \pm 1$ \\
\hline 90 & 10 & $50 \pm 4$ & $802 \pm 20(35)$ & $1303 \pm 17$ & $23 \pm 1$ & $82 \pm 2$ \\
\hline \multicolumn{7}{|l|}{ ABS } \\
\hline 100 & 0 & $60 \pm 0$ & $1044 \pm 18$ & $1186 \pm 16$ & $29 \pm 0$ & $87 \pm 1$ \\
\hline 98 & 2 & $61 \pm 1$ & $1001 \pm 15$ & $1209 \pm 11$ & $29 \pm 0$ & $81 \pm 3$ \\
\hline 94 & 6 & $70 \pm 2$ & $911 \pm 52(13)$ & $1252 \pm 26$ & $25 \pm 0$ & $83 \pm 1$ \\
\hline 90 & 10 & $68 \pm 4$ & $800 \pm 45(23)$ & $1279 \pm 40$ & $22 \pm 2$ & $81 \pm 4$ \\
\hline \multicolumn{7}{|l|}{ SAN } \\
\hline 100 & 0 & $56 \pm 4$ & $1113 \pm 35$ & $1132 \pm 15$ & $30 \pm 0$ & $83 \pm 2$ \\
\hline 98 & 2 & $60 \pm 2$ & $1036 \pm 45(7)$ & $1189 \pm 9$ & $29 \pm 1$ & $84 \pm 1$ \\
\hline 94 & 6 & $62 \pm 0$ & $822 \pm 19(26)$ & $1248 \pm 22$ & $26 \pm 0$ & $82 \pm 3$ \\
\hline 90 & 10 & $56 \pm 2$ & $687 \pm 47(38)$ & $1347 \pm 60$ & $19 \pm 2$ & $85 \pm 5$ \\
\hline
\end{tabular}

$t_{\text {ign, }}$ Time to ignition; PHRR, peak heat release rate; SEA, specific extinction area; MLR, mass loss rate; THR, total heat released.

The PHRR reductions for styrenic polymer nanocomposites based on triclay, triclay II and triclay III at 5\% inorganic clay loading are listed in Table 4. PS nanocomposites show a gradually decreasing reduction in PHRR when the oligomerically-modified clay contains an increased inorganic content while SAN nanocomposites show the same reduction with the three oligomerically-modified clays. HIPS nanocomposites with triclay and triclay II have equally good reduction, 50\%, while HIPS nanocomposites with triclay III show a smaller reduction, $35 \%$. ABS nanocomposites with triclay show 35\% reduction in PHRR while ABS nanocomposites with triclay II and triclay III show $23 \%$ reduction. From XRD and TEM, it is clear that the clay is not well-dispersed in PS and HIPS nanocomposites but it is well-dispersed in ABS and SAN nanocomposites based on triclay III and the PHRR reductions from cone calorimetry also indicate the same result. In another words, there is a good correlation between clay dispersion and PHRR reduction: well-dispersed clay in the nanocomposites leads to a good reduction in PHRR while when the clay is not well-dispersed, only modest reductions, indicative of some amount of microcomposite formation, are observed. 
Table 4. PHRR reduction of styrenic polymer nanocomposites with different oligomerically-modified clays at $5 \%$ inorganic clay loading

\begin{tabular}{|l|l|l|l|l|}
\hline Oligomerically-modified clay & PHRR reduction & & & \\
\hline & PS & HIPS & ABS & SAN \\
\hline Triclay & 61 & 51 & 35 & 42 \\
\hline Triclay II & 51 & 49 & 23 & 40 \\
\hline Triclay III & 32 & 35 & 23 & 38 \\
\hline
\end{tabular}

\subsection{Mechanical properties}

The mechanical properties of virgin polymers and their nanocomposites, including tensile strength, Young's modulus and elongation at break, have been evaluated and the data are tabulated in Table 5. The mechanical properties of the SAN nanocomposites are not reported due to difficulty in preparing the samples. The tensile strength is slightly increased for PS and ABS nanocomposites and it is not changed for HIPS nanocomposites, compared with the virgin polymers. All the nanocomposites have an increased Young's modulus. The biggest increase is for polystyrene nanocomposites containing $5 \%$ inorganic clay, where Young's modulus is improved by $40 \%$, which is about the same as seen in PS/triclay II nanocomposite. The elongation at break for these nanocomposites drops, just as in other styrenic polymer-clay systems. Compared with the mechanical properties of the nanocomposites based on triclay and triclay II, the nanocomposites based on triclay III exhibit a suppressed plasticizing effect with a limited improvement in Young's modulus.

Table 5. Tensile properties of styrenic polymers and their nanocomposites

\begin{tabular}{|c|l|l|l|l|}
\hline & Triclay III & Tensile strength (MPa) & Modulus (MPa) & Elongation (\%) \\
\hline 100 & 0 & $32 \pm 1$ & $1758 \pm 144$ & $3 \pm 1$ \\
\hline 97 & 2 & $37 \pm 3$ & $1956 \pm 86$ & $3 \pm 0$ \\
\hline 92 & 6 & $40 \pm 2$ & $2129 \pm 127$ & $2 \pm 1$ \\
\hline 88 & 10 & $38 \pm 2$ & $2405 \pm 168$ & $2 \pm 1$ \\
\hline HIPS & & & & \\
\hline 100 & 0 & $19 \pm 1$ & $1282 \pm 98$ & $36 \pm 2$ \\
\hline 97 & 2 & $18 \pm 2$ & $1331 \pm 45$ & $17 \pm 1$ \\
\hline 92 & 6 & $18 \pm 1$ & $1310 \pm 103$ & $2 \pm 1$ \\
\hline 88 & 10 & $18 \pm 1$ & $1382 \pm 77$ & $2 \pm 1$ \\
\hline ABS & & & & \\
\hline 100 & 0 & $25 \pm 2$ & $1112 \pm 115$ & $39 \pm 4$ \\
\hline 97 & 2 & $27 \pm 1$ & $1180 \pm 138$ & $22 \pm 2$ \\
\hline 92 & 6 & $27 \pm 2$ & $1255 \pm 56$ & $3 \pm 1$ \\
\hline 88 & 10 & $29 \pm 2$ & $1387 \pm 45$ & $2 \pm 1$ \\
\hline
\end{tabular}

The intent of this study was to ascertain if varying the inorganic content of oligomerically-modified clays had an effect on their dispersion and fire and mechanical properties in styrenics polymers. It is clear that the mechanical properties should be affected, because the higher organic content will cause plasticization and so it was not a surprise to find that the mechanical properties were improved when the organic content was lowered. It is not obvious what effect a change in composition might have on the dispersability of the clay. One might opine that, if these were prepared by bulk polymerization, there should be no effect. On the other hand, when nanocomposites are prepared by a mixing process, the organic content is critical to success. The general rule is that for bulk polymerization, one long chain is sufficient while for mixing, two chains are needed $\stackrel{[15]}{\text {. The most }}$ significant question concerns the possible pinning of clay layers due to the presence of multiple ammonium ions in each oligomer chain. One might expect that pinning must occur in this situation but the data do not support complete pinning and further investigations are required to understand this phenomenon. 


\section{Conclusions}

Styrenic polymer-clay nanocomposites were prepared by melt blending of the polymers with an oligomerically-modified clay, triclay III. PS and HIPS nanocomposites have a largely immiscible morphology while SAN and ABS nanocomposites have a mixed intercalated/delaminated morphology, based on XRD, TEM and cone calorimetry. The plasticizing effect from the oligomer was successfully suppressed by increasing the inorganic clay content to $50 \%$. Young's modulus of the material was enhanced by nanocomposite formation while tensile strength was maintained. Thermogravimetric analysis shows that the nanocomposite formation has only a small effect on thermal stability. The decreased organic content of the clays reduces plasticization, giving better mechanical properties, but it also has a very adverse effect on the dispersability of the clay in the polymer, leading to morphological changes from nanocomposites to microcomposites with polystyrene.

\section{References}

[1] E.P. Giannelis. Polymer layered silicate nanocomposites. Adv Mater, 8 (1996), pp. 29-35

[2] M. Alexandre, P. Dubois. Polymer-layered silicate nanocomposites: preparation, properties and uses of a new class of materials. Mater Sci Eng, R28 (2000), pp. 1-63

[3] T. Lan, P.D. Kaviratna, T.J. Pinnavaia. On the nature of polyimide-clay hybrid composites. Chem Mater, 6 (1994), pp. 573-575

[4] J.W. Gilman. Flammability and thermal stability studies of polymer layered-silicate (clay) nanocomposites. Appl Clay Sci, 15 (1999), pp. 31-49

[5] J. Zhu, A.B. Morgan, F.J. Lamelas, C.A. Wilkie. Fire properties of polystyrene-clay nanocomposites. Chem Mater, 13 (2001), pp. 3774-3780

[6] X. Zheng, C.A. Wilkie. Flame retardancy of polystyrene nanocomposites based on an oligomeric organicallymodified clay containing phosphate. Polym Degrad Stab, 81 (2003), pp. 539-550

[7] S. Su, D.D. Jiang, C.A. Wilkie. Study on the thermal stability of polystyryl surfactants and their modified clay nanocomposites. Polym Degrad Stab, 84 (2004), pp. 269-277

[8] S. Su, D.D. Jiang, C.A. Wilkie. Poly(methyl methacrylate), polypropylene and polyethylene nanocomposites formation by melt blending using novel polymerically-modified clays. Polym Degrad Stab, 83 (2004), pp. 321-331

[9] S. Su, D.D. Jiang, C.A. Wilkie. Novel polymerically-modified clays permit the preparation of intercalated and exfoliated nanocomposites of styrene and its copolymers by melt blending. Polym Degrad Stab, 83 (2004), pp. 333-346

[10] J. Zhang, D.D. Jiang, C.A. Wilkie. Polyethylene and polypropylene nanocomposites based upon an oligomerically modified clay. Thermochim Acta, 430 (2005), pp. 107-113

[11] J. Zhang, D.D. Jiang, C.A. Wilkie. Fire properties of styrenic polymer-clay nanocomposites based on an oligomerically-modified clay. Polym Degrad Stab, 91 (2006), pp. 358-366.

J. Zhang, D.D. Jiang, C.A. Wilkie. Polyethylene and polypropylene nanocomposites based on a three component oligomerically-modified clay. Polym Degrad Stab, 91 (2006), pp. 641-648

[12] J. Zhang, D.D. Jiang, C.A. Wilkie. Thermal and flame properties of polyethylene and polypropylene nanocomposites based on an oligomerically-modified clay. Polym Degrad Stab, 91 (2006), pp. 298-304. J. Zhang, D.D. Jiang, D. Wang, C.A. WilkieMechanical and fire properties of styrenic polymer nanocomposites based on an oligomerically-modified clay. Polym Adv Technol, 16 (2005), pp. 800-806

[13] S. Su, D.D. Jiang, C.A. Wilkie. Polybutadiene modified clay and its nanocomposites. Polym Degrad Stab, 84 (2004), pp. 279-288. S. Su, D.D. Jiang, C.A. Wilkie. Polybutadiene modified clay and its polystyrene nanocomposites. J Vinyl Addit Technol, 10 (2004), pp. 44-51

[14] M. Sepehr, L.A. Utracki, X. Zheng, C.A. Wilkie. Polystyrenes with macro-intercalated organoclay. Part I: compounding and characterization Polymer, 46 (2005), pp. 11557-11568.

M. Sepehr, L.A. Utracki, X. Zheng, C.A. Wilkie. Polystyrenes with macro-intercalated organoclay. Part II: rheology and mechanical performance. Polymer, 46 (2005), pp. 11569-11581 
[15] J.W. Gilman, T. Kashiwagi, M. Nyden, J.E.T. Brown, C.L. Jackson, S. Lomakin, et al. Flammability studies of polymer layered silicate nanocomposites: polyolefin, epoxy, and vinyl ester resins. S. AlMaliaka, A. Golovoy, C.A. Wilkie (Eds.), Chemistry and technology of polymer additives, Blackwell Scientific, London (1998), pp. 249-265

[16] A.B. Morgan, J.W. Gilman. Characterization of polymer-layered silicate (clay) nanocomposites by transmission electron microscopy and X-ray diffraction: a comparative study. J Appl Polym Sci, 87 (2003), pp. 1329-1338

[17] J. Zhu, F.M. Uhl, A.B. Morgan, C.A. Wilkie. Studies on the mechanism by which the formation of nanocomposites enhances thermal stability. Chem Mater, 13 (2001), pp. 4649-4654

[18] M. Zanetti, G. Camino, D. Canavese, A.B. Morgan, F.J. Lamelas, C.A. Wilkie. Fire retardant halogenantimony-clay synergism in polypropylene layered silicate nanocomposites. Chem Mater, 14 (2002), pp. 189-193

[19] J. Zhu, P. Start, K.A. Mauritz, C.A. Wilkie. Thermal stability and flame retardancy of poly(methyl methacrylate)-clay nanocomposites. Polym Degrad Stab, 77 (2002), pp. 253-258

[20] S. Wang, Y. Hu, Z. Lin, Z. Gui, Z. Wang, Z. Chen, et al. Flammability and thermal stability studies of ABS/montmorillonite nanocomposite. Polym Int, 52 (2003), pp. 1045-1049

[21] B. Jang, C.A. Wilkie. The effects of clay on the thermal degradation behavior of poly(styrene-coacrylonitrile). Polymer, 46 (2005), pp. 9702-9713

[22] H.A. Stretz, M.W. Wootan, P.E. Cassidy, J.H. Koo. Effect of exfoliation on poly(styrene-coacrylonitrile)/montmorillonite nanocomposite flammability. Polym Adv Technol, 16 (2005), pp. 239248 